\title{
Physiological Exercise and Post-Exercise Effects of Inverse Sequences of Combined Bench-Step Aerobics and Resistance Exercise
}

\author{
by \\ Catarina Abrantes ${ }^{1,2}$, Susana Martins ${ }^{1}$, Ana Pereira ${ }^{1,3}$, Fernando Policarpo ${ }^{4}$, \\ Isabel Machado ${ }^{1}$, Nelson Sousa ${ }^{1,2}$
}

The purpose of this study was to compare the effects of using inverse sequences of combined bench-step aerobics and resistance exercise on cardiorespiratory, hemodynamic and perceptual variables during exercise and one-hour postexercise. The tested sequences were bench-step aerobics immediately before and immediately after resistance exercise. Thirteen apparently healthy and physically active women (age $=21.9 \pm 6.1$ years, body height $=160 \pm 0.1 \mathrm{~cm}$, body mass $=58.8 \pm 7.5 \mathrm{~kg}$, estimated fat mass $=17.2 \pm 2.0 \%$ and estimated maximal oxygen uptake $=37.5 \pm 2.6 \mathrm{~mL} \cdot \mathrm{kg}$ 1.min-1) performed a 20-minute bench-step aerobics routine, immediately before (STEP_RES) and after (RES_STEP) resistance exercise. Oxygen uptake and heart rate were continuously measured, systolic and diastolic blood pressure, body temperature and perceived exertion were measured at rest, immediately after each type of exercise and at 15, 30, 45 and 60 min after exercise. When resistance exercise was performed first (RES_STEP), oxygen uptake was higher (23.2 \pm 3.9 vs. $20.5 \pm 4.8 \mathrm{~mL} \cdot \mathrm{kg}-1 \cdot \mathrm{min}-1)$, but the heart rate $(164.5 \pm 9.1 \mathrm{vs} .173 .9 \pm 11.7 \mathrm{bpm})$ and body temperature $(36.5 \pm$ 0.4 vs. $\left.37.6 \pm 0.6{ }^{\circ} \mathrm{C}\right)$ were lower. In both sequences, the type of exercise performed first was pointed out with a lower perceived exertion or lower perceived intensity. Exercise and 60-min post-exercise blood pressure had a similar response in both sequences, and systolic blood pressure along with diastolic blood pressure were lower than pre-exercise from 30 min until 60 min post-exercise. The results suggest that the sequence affected oxygen uptake and perceived exertion during exercise and that this total workload, despite the sequence, promoted a post-exercise blood pressure decrease in normotensive participants.

Key words: blood pressure, oxygen uptake, perceived exertion, post-exercise hypotension, EPOC, combined exercise.

\section{Introduction}

Physically active people often perform aerobic and resistance exercises within the same training session in time-saving strategy to benefit from specific adaptations of both types of exercise. Some studies suggest that combining these two types of exercise can improve long-term cardiorespiratory fitness and musculoskeletal function (Izquierdo et al., 2004; Kang et al., 2009;
Kraemer et al., 2001), but others found that such combinations result in lower magnitude responses when compared to each type of exercise being performed separately (Kraemer et al., 1995; Larose et al., 2012; Nelson et al., 1990; Schumann et al., 2015).

The acute physiological effects of isolated or combined exercise (aerobic and resistance), in general, are increases in the heart rate (HR),

\footnotetext{
1 - Research Center in Sports Sciences, Health Sciences and Human Development, CIDESD, GERON Research Community, Vila Real, Portugal.

2 - Exercise and Health Department, University of Trás-os-Montes and Alto Douro, Vila Real, Portugal.

3 - Research Community, Polytechnic Institute of Setúbal, School of Education, Setúbal, Portugal.

4 - Faculdades integradas de Patos, Laboratory of Bioscience of Human Movement, Federal University of Rio de Janeiro, Rio de Janeiro, Brazil.
} 
energy expenditure, oxygen uptake $\left(\mathrm{VO}_{2}\right)$, blood pressure (BP), metabolic rate and related thermic effect. When combined in the same exercise session, resistance exercise performed before aerobic exercise has been related with a higher lipolysis rate and total exercise energy expenditure (Kang et al., 2009; Goto et al., 2005). In contrast, when resistance exercise is performed after aerobic exercise there seems to be an increase in post-exercise oxygen uptake (Drummond et al., 2005). Additionally, there is a higher HR, perceived exertion (RPE) and $\mathrm{VO}_{2}$ during aerobic exercise when it is performed after resistance exercise (Drummond et al., 2005). The BP increases during exercise and decreases afterwards, often to values below those measured pre-exercise (Keese et al., 2011; MacDonald, 2002; MacDonald et al., 1999; Rezk et al., 2006). This repeated post-exercise BP effect has been identified as an important non-pharmacologic strategy for the prevention of hypertension and other lifestyle diseases (Pescatello et al., 2004), occurring with higher magnitude after more intense cardiovascular exercise (Forjaz et al., 2004; Pescatello et al., 2004) and in low- to moderateintensity resistance exercise (Rezk et al., 2006).

The post-exercise BP effect of combined aerobic and resistance exercise seems similar to isolated aerobic exercise, and is more effective than isolated resistance exercise; however, the available studies present variated methodologies that often compare different exercise doses and, also, methodologies that do not identify the effects of inversing the sequence. Despite all, it seems clear that previous intensity and the type of exercise play an important role in physiological variables related to metabolic, hemodynamic and thermoregulatory specific responses.

Therefore, the purpose of the present study was to compare the effects of using inverse sequences of combined bench-step aerobics and resistance exercise on cardiorespiratory, hemodynamic and perceptual variables during exercise and one-hour post-exercise. The tested sequences were bench-step aerobics immediately before (STEP_RES) and immediately after (RES_STEP) two sets of low-weight high-volume resistance exercises. We hypothesized that despite the similarity of total combined exercise load of bench-step aerobics exercise and low-weight highvolume resistance exercise, changing the sequence would affect the exercise and post-exercise physiological responses.

\section{Methods}

Participants

The sample comprised 13 female volunteers, university students, who met the inclusion criteria of being physically active (Pollock et al., 1998), apparently healthy (reporting no metabolic, cardiovascular or respiratory diseases, neither cardiovascular risk factors), taking no medications and had regular menstrual cycles (controlled during the 6 months before data collection) (Table 1). Participants were familiarized with bench-step aerobics and resistance exercises, due to their previous experience from the Sport Sciences bachelor curriculum. All participants were informed of the study procedures and gave their written positive consent. The procedures followed the Declaration of Helsinki and a national institution authority review board granted ethical approval (PEstOE/SAU/UI4045/2013).

For the protocol preparation, participants were asked not to ingest alcohol or caffeine and to refrain from exercise during the 48 hours before the experiment. They were advised to drink 33 $\mathrm{mL} \cdot \mathrm{kg}^{-1}$ body-weight of water during the 24 hours before the experiment and $5-7 \mathrm{~mL} \cdot \mathrm{kg}^{-1}$ bodyweight during the three hours preceding the data collection. They completed a 1-day food diary on the day before the first experimental trial and repeated the diary before the second trial.

\section{Measures}

Maximum-strength was measured to adjust the exercise load, using the 1-RM method as described earlier by Kraemer and Fry (1995). The re-test was performed after one week and showed high intra-class correlation coefficients (Table 1). To predict maximal aerobic power $\left(\mathrm{VO}_{2 \max }\right)$, the Queens-College Step-Test was used accordingly to instructions previously described (Mcardle et al., 1972) and $\mathrm{VO}_{2 \max }$ was derived from the equation (1): $\mathrm{VO}_{2 \max }\left(\mathrm{ml} \cdot \mathrm{kg}^{-1} \cdot \mathrm{min}^{-1}\right)=$ $65.81-(0.1847 \cdot \mathrm{HR})$.

$\mathrm{VO}_{2}$ and the HR were measured using a gas analyzer (COSMED® K4b2, Rome, Italy) with a transmitter band (T61 Polar ${ }^{\circledR}$, Kempele, Finland). Breath-by-breath and beat-by-beat data were smoothed to one-min average. After $15 \mathrm{~min}$ in a sitting position, the average HR and gases of 
the last $10 \mathrm{~min}$ were used for pre-exercise data. For the exercise data, the average values of each $20 \mathrm{~min}$ bench-step and $10 \mathrm{~min}$ of resistance exercise were used. The average values of the first 15 min after exercise were used for $\mathrm{VO}_{2}$ postexercise data. The system was calibrated according to the manufacturer's instructions (COSMED ${ }^{\circledR}$ K4b2, Rome, Italy).

The BP was measured using an aneroid sphygmomanometer (Artsana, Standard, Italy). In the last minute of the pre-exercise period and during recovery (at the $14^{\text {th }}, 29^{\text {th }}, 44^{\text {th }}$ and $59^{\text {th }}$ $\mathrm{min})$, the measurements were performed with participants seated quietly. To measure the BP, immediately after the bench-step and each resistance exercise set (the average value was used), the measurements were performed in a standing position to avoid the postural variation effect on BP. All measurements were done by the same technician and according to standardized instructions (Netea et al., 2003).

The exercise rate pressure product, that is considered a relevant indirect marker of myocardial requirements, was calculated for each type of exercise (i.e. bench-step aerobics and resistance exercises) according to the equation (2): $\mathrm{RPP}=\mathrm{HR} \cdot \mathrm{SBP} / 1000$.

Body temperature was measured with an auricular thermometer (ThermoScan Plus IRT 3520 , Braun) during the $10^{\text {th }}$ and $20^{\text {th }}$ min for the bench-step exercise routine and after each resistance exercise set, in the $14^{\text {th }}, 29^{\text {th }}, 44^{\text {th }}$ and $59^{\text {th }}$ min of recovery, and two measurements were taken to calculate the arithmetic mean.

The physiologic strain index (a physiological marker that combines cardiovascular and thermoregulatory responses) was calculated for each type of exercise according to Moran et al. (1998) equation (3): PSI= [5 (TtyT Ttyo) - (39.5 - Ttyo) - $1+5$ (HRT - HRo) · (180 HRo) - 1] where Ttyo and HRo were the baseline aural canal temperature and heart rate measurements and TtyT and HRT were the endpoint aural canal temperature and heart rate measurements.

The RPE was measured using the 6-20 Borg scale at minutes 10 and 20 for the bench-step exercise routine and after each resistance exercise set according to normalized instructions (Borg, 1985) and the average was used to establish the exercise values.

\section{Design and Procedures}

Each participant went to the laboratory on seven occasions comprehending: study clarification, characterization and maximal aerobic power testing, familiarization with the resistance exercises and one-repetition maximum (1-RM) testing and two experimental trials. The two trials were randomly assigned, started at the same hour, and were separated by 72 hours to seven days to ensure complete recovery and were performed during the follicular phase of the menstrual cycle.

The low-weight high-volume resistance protocol consisted of a circuit of two sets of five exercises at 50\% 1-RM with the same 1-RM test order: (a) bent-over row; (b) squat shoulder width; (c) biceps curl; (d) squat beyond shoulder width; and (e) deltoid (shoulder lateral abduction). The resistance exercises were performed with free weights and supervised to ensure adequate technique, intensity and cadence ( $2.0 \mathrm{~s}$ for the concentric and $2.0 \mathrm{~s}$ for the eccentric phase) and to perform the repetitions within a full range of motion (until failure). The rest interval between sets and exercises was very short and allowed only to change the weight and body position.

The bench-step aerobics routine consisted of $20 \mathrm{~min}$ of uninterrupted steady-state exercise performed on a $20 \mathrm{~cm}$ bench-step platform (Reebok $\left.{ }^{\circledR}\right)$, with music at a cadence of $132 \mathrm{bpm}$ (Table 2). The exercise was performed individually, although it is not the common method for bench-step aerobics, and the exercise target zone was set between $70-89 \%$ of heart rate reserve (HRR) according to consensual guidelines (Garber et al., 2011). Participants were verbally encouraged to maintain appropriate technical movements.

\section{Testing day procedures}

On the experimental days, participants arrived at the laboratory $30 \mathrm{~min}$ before beginning the exercise protocol, and remained seated while the HR monitor and the gas analyzer vest were fixed (Hans Rudolph, Kansas City, USA). After these procedures, they were asked to remain seated and inactive in a chair for 15 minutes (preexercise). After the pre-exercise period, participants performed a two-min standardized step warm-up (Table 2), followed by one of the STEP_RES or RES_STEP sequences. 
From the beginning of the pre-exercise period, $\mathrm{VO}_{2}, \mathrm{VCO}_{2}$ and $\mathrm{VE}$ and $\mathrm{HR}$ were continuously measured during the exercise trial and through 15 minutes of recovery, with the HR being measured until the end of recovery. The systolic blood pressure (SBP), diastolic blood pressure (DBP) and body temperature were measured in the last minute of the pre-exercise period, immediately after the end of the step routine, and after each resistance exercise set. Immediately after, participants remained seated and quiet for $60 \mathrm{~min}$ (divided into four periods of 15 min of recovery), during which BP and body temperature were measured in the last minute of each 15 min period. The RPE was measured in the middle and at the end of the bench-step exercise routine and after each set of resistance exercise.

The environment temperature $(23-25 \stackrel{\circ}{\circ} \mathrm{C})$, atmospheric pressure $(712-720 \mathrm{mmHg})$ and relative humidity $(45-50 \%)$ were controlled during all trials. Participants used the same sportswear and sneakers in both experimental trials.

\section{Statistical analysis}

All data were inspected using box-andwhiskers plots to identify outliers and data entry errors. The distributions were tested using the Shapiro-Wilk test. The paired sample student $t-$ test was used to ensure similar pre-exercise conditions in all variables, and also to test for differences between STEP_RES and RES_STEP sequences, during bench-step and resistance exercises. The Wilcoxon test was used when nonnormal distributions were identified. Repeated measures ANOVA $(2 \times 5)$ was used to test the post-exercise effect of the session sequence (STEP_RES and RES_STEP) in five periods (preexercise and post-exercise split into 4 periods) and was followed by a posthoc comparison to identify differences between periods. Cohen's d effect sizes and eta square values $\left(\eta^{2}\right)$ were applied to identify the magnitude of differences. All analyses were carried out using the SPSS (Version 16.0, Chicago, IL) and an alpha level of 5\%.

\section{Results}

There were no differences between preexercise values of $\mathrm{VO}_{2}, \mathrm{SBP}, \mathrm{DBP}, \mathrm{HR}$, and body temperature, confirming identical conditions for both experimental trial sequences (STEP_RES and RES_STEP). During the bench-step exercise, the participants' HRR percentage was $81 \%$ in STEP_RES and $82 \%$ in RES_STEP. During the resistance exercise, a higher volume (weight $x$ repetition $\times$ set) was performed during the RES_STEP sequence than in the STEP_RES sequence for all resistance exercises. However, there were differences only in the biceps curl $(p=$ $0.003)$.

No differences were found in SBP, DBP and RPP responses between STEP_RES and RES_STEP sequences in any studied period during exercise and post-exercise periods. However, the session sequence promoted a singular effect on $\mathrm{VO}_{2}, \mathrm{HR}$, RPE, body temperature and PSI response during the exercise (Table 3).

The RES_STEP sequence promoted higher $\mathrm{VO}_{2}(p=0.020)$ and a lower HR $(p=0.015)$ during the resistance exercise; however, during benchstep aerobics exercise, HR values were similar for both STEP_RES and RES_STEP sequences. The body temperature was significantly higher at the STEP_RES session sequence during both benchstep aerobics $(p=0.029)$ and resistance $(p<0.001)$ exercise. The PSI was significantly higher during the later resistance exercise in the STEP_RES sequence $(p<0.001)$. The RPE was significantly higher during the later performed type of exercise despite the sequence of the session; during benchstep aerobics $(p=0.003)$ in the RES_STEP sequence, and during resistance exercise $(p=$ 0.018) in the STEP_RES sequence (Table 3).

The session sequence did not affect the post-exercise response of SBP $\left(\mathrm{F}_{1,12}=1.3, p=0.28\right)$, $\operatorname{DBP}\left(\mathrm{F}_{1,12}=1.4, p=0.261\right)$, HR $\left(\mathrm{F}_{1,12}=3.2, p=0.101\right)$ and BT $\left(\mathrm{F}_{1}, 12=1.8, p=0.21\right)$. During the postexercise period there were differences for SBP $\left(\mathrm{F}_{1}\right.$, $\left.12=26.1, p=0.000, \eta^{2}=0.685\right), \mathrm{DBP}\left(\mathrm{F}_{1,12}=5.6, p=\right.$ $\left.0.001, \eta^{2}=0.317\right), \operatorname{HR}\left(\mathrm{F}_{1,12}=120.8, p=0.000, \eta^{2}=\right.$ $0.910)$ and BT $\left(\mathrm{F}_{1,12}=4.7, p=0.003, \eta^{2}=0.282\right)$ related to rest values. The post-hoc comparisons revealed that independently of the sequence, the SBP responses were lower than pre-exercise during all post-exercise periods $(p \leq 0.001)$, with a continuous decrease until P45, followed by a rise (Table 4). There were also differences between P15 and P30 $(p=0.047), \mathrm{P} 15$ and P45 $(p=0.001)$ and $\mathrm{P} 15$ and P60 $(p=0.005)$. No significant differences were found in DBP responses between the preexercise period and P15, although a significant decrease in DBP to below pre-exercise value 
during the post-exercise periods P30, P45 and P60 was noted $(p \leq 0.05)$. In addition, there were differences between P15 and P30 ( $p=0.012)$, P15 and P45 $(p=0.005)$ and P15 and P60 $(p=0.013)$.

Independently of the session sequence, the HR was also significantly different between $\mathrm{P} 15$ and the following post-exercise periods (P30,
P45 and P60, $p \leq 0.05)$, and between P30 and P45 $(p=0.001)$. The pre-exercise body temperature remained similar to P15 and P30, but different during P45 $(p=0.026)$ and P60 $(p=0.003)$. Also, there were differences between P15 and P45 ( $p=$ $0.018), \mathrm{P} 15$ and $\mathrm{P} 60(p=0.002), \mathrm{P} 30$ and $\mathrm{P} 45(p=$ $0.044)$ and $\mathrm{P} 30$ and $\mathrm{P} 60(p=0.017)$.

Table 1

Physical and physiological characteristics of participants $(N=13)$, the values are presented as mean and standard deviations (SD) and intra-class correlation coefficients (ICC).

\begin{tabular}{lc}
\hline Variables & Mean \pm SD \\
\hline Age (years) & $21.9 \pm 6.1$ \\
Height $(\mathrm{cm})$ & $160.6 \pm 0.1$ \\
Body mass $(\mathrm{kg})$ & $58.8 \pm 7.5$ \\
Fat mass $(\%)$ & $17.2 \pm 2.0$ \\
$\mathrm{VO}_{2 \text { max, }}$ predicted $\left(\mathrm{mL} \cdot \mathrm{kg}^{-1} \cdot \mathrm{min}^{-1}\right)$ & $37.5 \pm 2.6$ \\
Systolic Blood Pressure $\left(\mathrm{mmHg}^{-1}\right)$ & $114.0 \pm 9.6$ \\
Diastolic Blood Pressure $(\mathrm{mmHg})$ & $69.5 \pm 8.6$ \\
HRmax, predicted (bpm) & $204.1 \pm 6.1$ \\
1-RM free weight test & \\
Bent-over Row $(\mathrm{kg})$ & $12.5 \pm 2.5(\mathrm{ICC}=0.97)$ \\
Squat shoulder width $(\mathrm{kg})$ & $50.7 \pm 0.2(\mathrm{ICC}=0.98)$ \\
Biceps Curl shoulder width $(\mathrm{kg})$ & $8.6 \pm 2.06(\mathrm{ICC}=0.98)$ \\
Squat beyond shoulders width $(\mathrm{kg})$ & $50.7 \pm 0.2(\mathrm{ICC}=0.98)$ \\
Deltoid shoulder width $(\mathrm{kg})$ & $6.8 \pm 1.3(\mathrm{ICC}=0.95)$ \\
\hline
\end{tabular}

Table 2

Bench-step aerobics exercise warm-up and choreography format with first and second 32 counts routines.

\begin{tabular}{|c|c|c|c|c|}
\hline $\begin{array}{l}\text { Basic bench-step } \\
\text { movements }\end{array}$ & $\begin{array}{l}\text { Leader } \\
\text { foot }\end{array}$ & Repetitions & Counts & Arm movements \\
\hline \multicolumn{5}{|l|}{ Warm up } \\
\hline Alternated knee & Right/Left & 4 & 16 & Lateral pull down (8 times) \\
\hline Basic step & Right & 2 & 8 & Front pull down (4 times) \\
\hline Three knee repeaters & Right & 1 & 8 & 90 degrees arms butterfly (3 times) \\
\hline \multicolumn{5}{|l|}{ Start with left foot } \\
\hline \multicolumn{5}{|l|}{$1^{\text {st }}$ routine } \\
\hline Basic step with propulsion & Right & 2 & 8 & Alternated biceps curl (4 times) \\
\hline Alternated knee & Right/Left & 2 & 8 & Lateral pull down (4 times) \\
\hline V step & Right & 2 & 8 & Alternated overhead arm elevation ( 2 times) \\
\hline Three knee repeaters & Right & 1 & 8 & 90 degrees arms butterfly (3 times) \\
\hline \multicolumn{5}{|l|}{ Start with left foot } \\
\hline \multicolumn{5}{|l|}{$2^{\text {nd }}$ routine } \\
\hline $\begin{array}{l}\text { Basic step with backward } \\
\text { lunge }\end{array}$ & Right & 1 & 8 & $\begin{array}{l}\text { Elevated arms in front at shoulders line ( } 2 \\
\text { times) }\end{array}$ \\
\hline Leg flexion & Right/Left & 2 & 8 & Upright row arms \\
\hline Backward leg extension & Right/Left & 2 & 8 & Arms forward fully extended \\
\hline $\begin{array}{l}\text { Three alternated knee } \\
\text { repeaters }\end{array}$ & Right & 1 & 8 & $\begin{array}{l}\text { Alternated } 90 \text { degrees arms butterfly ( } 3 \\
\text { times) }\end{array}$ \\
\hline Start with left foot & & & & \\
\hline
\end{tabular}


Table 3

Blood pressure, cardiovascular, respiratory and perceptual responses during benchstep aerobics and resistance exercise periods for the inverse session sequence (STEP_RES and RES_STEP).

\begin{tabular}{|c|c|c|c|c|}
\hline & \multicolumn{2}{|c|}{ STEP_RES } & \multicolumn{2}{|c|}{ RES_STEP } \\
\hline $\begin{array}{l}\text { Variables } \\
\text { SBP } \\
\text { (mmHg) }\end{array}$ & $\begin{array}{l}\text { Bench-Step } \\
127.9 \pm 19.9\end{array}$ & $\begin{array}{l}\text { Resistance } \\
118.8 \pm 9.6\end{array}$ & $\begin{array}{l}\text { Resistance } \\
123.4 \pm 9.7\end{array}$ & $\begin{array}{l}\text { Bench-Step } \\
124.0 \pm 13.3\end{array}$ \\
\hline $\begin{array}{l}\text { DBP } \\
(\mathrm{mmHg})\end{array}$ & $64.9 \pm 6.4$ & $63.2 \pm 5.3$ & $65.7 \pm 6.2$ & $64.5 \pm 5.8$ \\
\hline $\begin{array}{l}\mathrm{VO}_{2} \\
\left(\mathrm{~mL} \cdot \mathrm{kg}^{-1} \cdot \mathrm{min}^{-1}\right)\end{array}$ & $33.2 \pm 5.0$ & $\begin{array}{c}20.5 \pm 4.8^{*} \\
\mathrm{ES}=2.63\end{array}$ & $23.2 \pm 3.9$ & $32.6 \pm 4.4$ \\
\hline $\begin{array}{l}\text { HR } \\
\text { (beats·min-1) }\end{array}$ & $179.2 \pm 7.5$ & $\begin{array}{c}173.9 \pm 11.7^{*} \\
\mathrm{ES}=0.74\end{array}$ & $164.5 \pm 9.1$ & $181.0 \pm 7.0$ \\
\hline $\begin{array}{l}\text { BT } \\
\left({ }^{\circ} \mathrm{C}\right)\end{array}$ & $\begin{array}{c}37.6 \pm 0.5^{*} \\
\mathrm{ES}=2.43\end{array}$ & $\begin{array}{c}37.6 \pm 0.6^{*} \\
\mathrm{ES}=0.62\end{array}$ & $36.5 \pm 0.4$ & $37.2 \pm 0.7$ \\
\hline $\begin{array}{l}\text { RPP } \\
(\mathrm{mmHg} \cdot \mathrm{bpm})\end{array}$ & $22856 \pm 3423$ & $20693 \pm 2323$ & $20308 \pm 1799$ & $22448 \pm 2620$ \\
\hline $\begin{array}{l}\text { PSI } \\
(0-10)\end{array}$ & $6.39 \pm 1.25$ & $\begin{array}{c}6.19 \pm 1.32 * \\
E S=2.00\end{array}$ & $3.80 \pm 1.18$ & $5.66 \pm 1.84$ \\
\hline $\begin{array}{l}\text { RPE } \\
(6-20)\end{array}$ & $\begin{array}{c}13.2 \pm 1.4^{*} \\
\mathrm{ES}=0.56\end{array}$ & $\begin{array}{c}15.7 \pm 7.9^{*} \\
\mathrm{ES}=0.21 \\
\end{array}$ & $13.9 \pm 1.1$ & $14.5 \pm 1.9$ \\
\hline
\end{tabular}

Legend: STEP_RES = bench-step and resistance exercise sequence; $R E S$ _STEP $=$ resistance exercise and bench-step sequence; $E S=$ Effect size; ${ }^{*}=$ significantly different from the identical type of exercise in

RES_STEP. The mean values and standard deviation are given for systolic blood pressure (SBP), diastolic blood pressure (DBP), oxygen uptake $\left(V_{2}\right)$, heart rate $(\mathrm{HR})$, body temperature $(\mathrm{BT})$, rate pressure product (RPP), physiologic strain index (PSI 0-10 scale) and perceived exertion (RPE).

Table 4

Blood pressure, cardiovascular, respiratory and perceptual responses during post-exercise for the inverse session sequence (STEP_RES and RES_STEP).

\begin{tabular}{|c|c|c|c|c|c|c|c|c|c|c|}
\hline \multirow{3}{*}{ Variables } & \multirow{3}{*}{ Rest } & \multicolumn{4}{|c|}{ STEP_RES } & \multicolumn{5}{|c|}{ RES_STEP } \\
\hline & & \multicolumn{4}{|c|}{ Post-Exercise } & \multirow{2}{*}{ Rest } & \multicolumn{4}{|c|}{ Post-Exercise } \\
\hline & & P15 & P30 & P45 & P60 & & P15 & P30 & P45 & P60 \\
\hline $\begin{array}{l}\text { SBP } \\
(\mathrm{mmHg})\end{array}$ & $107.3 \pm 7.4$ & $100.0 \pm 4.7$ & $\begin{array}{l}97.1 \pm 7.5^{a} \\
E S:{ }^{a}=0.46\end{array}$ & $\begin{array}{l}96.6 \pm 5.4^{\mathrm{a}} \\
\text { ES: } \mathrm{a}^{\mathrm{a}}=0.67\end{array}$ & $\begin{array}{l}97.5 \pm 5.8^{\mathrm{a}} \\
\mathrm{ES}:{ }^{\mathrm{a}}=0.47\end{array}$ & $109.0 \pm 6.4$ & $102.5 \pm 7.8$ & $98.5 \pm 7.5$ & $96.5 \pm 6.1$ & $98 \pm 6.2$ \\
\hline $\begin{array}{l}\text { DBP } \\
(\mathrm{mmHg})\end{array}$ & $66.2 \pm 9.1$ & $66.1 \pm 7.5$ & $\begin{aligned} 64.2 & \pm 7.0^{\mathrm{a}} \\
\text { ES: } & =0.30\end{aligned}$ & $\begin{array}{c}59.8 \pm 4.0^{\mathrm{a}} \\
\text { ES: }{ }^{\mathrm{a}}=1.10\end{array}$ & $\begin{aligned} 60.9 & \pm 4.7^{\mathrm{a}} \\
\text { ES: } & =0.88\end{aligned}$ & $69.0 \pm 7.0$ & $68.9 \pm 10.0$ & $62.5 \pm 5.7$ & $64.5 \pm 6.9$ & $64.9 \pm 8.6$ \\
\hline $\begin{array}{l}\mathrm{VO}_{2} \\
\left(\mathrm{~mL} \cdot \mathrm{kg}^{-1} \cdot \mathrm{min}^{-1}\right)\end{array}$ & $4.8 \pm 1.0$ & $6.8 \pm 1.4$ & - & - & - & $4.6 \pm 1.1$ & $6.6 \pm 0.9$ & - & - & - \\
\hline $\begin{array}{l}\text { HR } \\
\text { (beats·min }{ }^{-1} \text { ) }\end{array}$ & $81.0 \pm 9.4$ & $118.0 \pm 12.2$ & $\begin{array}{l}97.2 \pm 11.1^{\mathrm{a}} \\
\text { ES: }{ }^{\mathrm{a}}=1.78\end{array}$ & $\begin{array}{c}92.8 \pm 10.8^{\mathrm{a} b} \\
\text { ES: }{ }^{\mathrm{a}}=2.19 \\
\text { ES: }{ }^{\mathrm{b}}=0.40\end{array}$ & $\begin{array}{l}90.2 \pm 11.1^{\mathrm{ab}} \\
\mathrm{ES}^{\mathrm{a}}=2.40, \\
\text { ES: }^{\mathrm{b}}=0.63\end{array}$ & $77.3 \pm 8.4$ & $115.0 \pm 12.5$ & $92.3 \pm 12.1$ & $89.6 \pm 10.0$ & $86.3 \pm 12.8$ \\
\hline $\begin{array}{l}\text { BT } \\
\left({ }^{\circ} \mathrm{C}\right)\end{array}$ & $36.9 \pm 0.3$ & $36.9 \pm 0.04$ & $36.8 \pm 0.5$ & $\begin{array}{l}36.5 \pm 0.5^{\mathrm{a} b} \\
\text { ES: }{ }^{\mathrm{a}}=1.13 \\
\mathrm{ES}: \mathrm{b}=0.85\end{array}$ & $\begin{array}{l}36.5 \pm 0.5 \mathrm{ab} \\
\text { ES: }{ }^{\mathrm{a}}=1.13 \\
\text { ES: } \mathrm{b}=0.85\end{array}$ & $36.9 \pm 0.4$ & $36.7 \pm 0.2$ & $36.6 \pm 0.4$ & $36.4 \pm 0.5$ & $36.3 \pm 0.3$ \\
\hline
\end{tabular}

Legend: $S T E P \_R E S=$ bench-step and resistance exercise sequence; $R E S \_S T E P=$ resistance exercise and bench-step sequence; $P 15=$ first $15 \mathrm{~min}$ post-exercise period; $P 30=$ second $15 \mathrm{~min}$ post-exercise period; $P 45=$ third $15 \mathrm{~min}$ postexercise period; $P 60=$ fourth 15 min post-exercise period; $E S=$ Effect size; ${ }^{a}=$ significantly different from $P 15, p<0.05$; $b=$ significantly different from P30, $p<0.05$. The mean values and standard deviation are given for systolic blood pressure (SBP), diastolic blood pressure (DBP), oxygen uptake $\left(V \mathrm{O}_{2}\right)$, heart rate (HR) and body temperature (BT). 


\section{Discussion}

This study revealed that the two sequences (STEP_RES and RES_STEP) promoted different responses in $\mathrm{VO}_{2}, \mathrm{HR}$, body temperature, PSI and RPE, yet similar responses in exercise $\mathrm{BP}$ and also during the $60 \mathrm{~min}$ of recovery. The $\mathrm{VO}_{2}$ and $\mathrm{HR}$ responses were similar during bench-step exercise, which was performed at similar HR values $(179 \pm 8 \mathrm{bpm}$ in STEP_RES sequence and $181 \pm 7 \mathrm{bpm}$ in RES_STEP sequence). However, during the resistance exercise of the RES_STEP sequence, the $\mathrm{VO}_{2}$ responses were $23.3 \pm 3.9 \mathrm{~mL} \cdot \mathrm{kg}-1 \cdot \mathrm{min}-1$, significantly higher than the $20.5 \pm 4.8 \mathrm{~mL} \cdot \mathrm{kg}$ $1 \cdot$ min-1 of STEP_RES sequence. This greater $\mathrm{VO}_{2}$ probably resulted from the higher total number of repetitions performed (reps $=169$ for RES_STEP and reps $=147$ for STEP_RES), the inexistence of previous muscle fatigue and the pattern of oxygen kinetics. The higher $H R$ responses in the resistance exercise in the STEP_RES sequence may be due to the sympathetic nervous system maintenance of the previous bench-step aerobic exercise. During the resistance exercise, a higher $\mathrm{HR}$ was associated with lower $\mathrm{VO}_{2}$ in the STEP_RES sequence. It appears that the previous vigorous bench-step aerobics type exercise affected the low-to-moderate resistance exercise and that the chosen intensity for the preceding type of exercise is an important issue to consider. In another study with low (60\% 8-RM) and high intensity resistance exercise (90\% 8-RM) followed by cardiovascular exercise, $\mathrm{VO}_{2}$ during the subsequent type of exercise was higher only after the high-intensity resistance exercise (Kang et al., 2009). Therefore, it seems that for energy expenditure benefits, resistance exercise performed before the cardiovascular exercise needs to be intense.

Excess post-exercise $\mathrm{VO}_{2}$ and the postexercise HR were higher during one-hour in both sequences, but the magnitude of change was similar in both exercise sequences. The slightly higher pattern in post-exercise $\mathrm{VO}_{2}$ and $\mathrm{HR}$ in the STEP_RES sequence did not achieve statistical significance. Usually, short-term excess postexercise $\mathrm{VO}_{2}$ is higher after high-intensity resistance exercise and is related to higher metabolic disruption (Borsheim and Bahr, 2003). In this study, the resistance exercise intensity did not promote a higher post-exercise response.
The exercise BP increases were of small magnitude. During bench-step aerobics the SBP was $127.9 \mathrm{mmHg}$ (STEP_RES) and $124.0 \mathrm{mmHg}$ (RES_STEP) and after resistance exercise, it was $118.8 \mathrm{mmHg}$ (STEP_RES) and $124.0 \mathrm{mmHg}$ (RES_STEP). Despite the timing of the measurement of the exercise BP (i.e. immediately after the end of each exercise), that can aggregate exercise and post-exercise $\mathrm{BP}$ responses, the resistance exercise was performed with a low load and high-volume dynamic contractions, promoting smaller exercise BP increases compared to traditional resistance exercise responses (Figueroa and Vicil, 2011; MacDonald, 2002). It should also be emphasized that in this study there were no specific weight-training procedures that promote exaggerated increases in muscle metaboreflex and mechanoreflex (mechanical compression of the blood vessels in the exercising muscle beds), and the Valsalva manoeuvre, which significantly increases intrathoracic pressure (Linsenbardt et al., 1992).

In the post-exercise period, the sequence effect (STEP_RES or RES_STEP) did not affect the acute BP responses, however, there were postexercise positive effects, possibly related to the total load. In fact, despite the sequence, SBP and DBP responses during recovery were significantly lower than pre-exercise and achieved a lower value at P45 (except for DBP in RES_STEP, with a lower value at P30). Also, the results revealed that the STEP_RES and RES_STEP sequences induced acute similar decreases in SBP $(10.7 \pm 2.0$ and 12.5 $\pm 0.3 \mathrm{mmHg}$, respectively) and DBP $(6.4 \pm 5.1$ and $6.5 \pm 1.3 \mathrm{mmHg}$, respectively) compared to rest. These results indicate that the higher magnitude of post-exercise BP in normotensive participants is attained before one-hour after exercise and longer duration of post-exercise measures is needed to determine the duration of the post-exercise hypotensive effect. The cardiovascular exercise intensity used in this study was nearly $80 \%$ of HRR, therefore, requiring the use of a significant muscle mass that can lead to great hemodynamic stress, higher levels of circulating catecholamine's, greater cardiac output, increased blood flow and $\mathrm{BP}$, and, therefore, greater stress (MacDonald, 2002). These factors lead to sustained vasodilation in active skeletal muscle, associated with a reduction in peripheral vascular resistance (enhanced by endothelial vasodilators such as 
nitric oxide, adenosine, prostaglandins, and thermodilatation), that affect the vasoconstrictor response to $\alpha$-adrenergic stimulation (Forjazet al., 1998; MacDonald, 2002; Smelker et al., 2004), promoting a BP decrease after exercise (MacDonald, 2002).

This combined aerobic and resistance exercise effect on post-exercise BP was already identified (Keese et al., 2011, 2012; Ruiz et al., 2011), as well as the lower post-exercise BP responses related to increased intensity of later aerobic exercise $\left(50 \%, 65 \%\right.$ and $80 \%$ of $\mathrm{VO}_{2}$ peak) (Keese et al., 2012). However, the sequence effect (i.e. aerobic followed by resistance or resistance followed by aerobic) is quite unknown in the current literature. The post-exercise BP reduction in RES_STEP was probably related to the total load and, thus, not affected by the sequence.

The body temperature was higher during both bench-step and resistance exercise in the STEP_RES sequence than in the RES_STEP sequence. The effect of high-intensity and high muscle mass mobilization in the bench-step exercise was probably maintained during the following resistance exercise, therefore, it started with higher body temperature. This cumulative effect was already identified in other studies and variables when a more intense exercise was performed first (Kang et al., 2003, 2009). Greater post-exercise oxygen uptake (Kang et al., 2003, 2009), HR, and fat oxidation (Kang et al., 2003) were found in a high-to-low exercise intensity sequence. The PSI, that reflects the combined load of the thermoregulatory and cardiovascular systems, was higher in resistance exercise only when performed after aerobic bench-step. It seems that the effect of previous bench-step aerobics type exercise on both thermoregulatory and cardiovascular responses, was maintained in the following responses to exercise.
The RPE was higher during the last type of exercise, independently of the session sequence, revealing an important cumulative effect. This fact is supported by the higher RPE values reported in the resistance exercise when performed after the bench-step aerobic exercise, compared with the same load performed before cardiovascular exercise $(15.7 \pm 7.9$ for STEP_RES vs. $13.9 \pm 1.1$ for RES_STEP). This effect is possibly explained by the previous exercise effects, like glycogen depletion, elevated blood lactate, HR and metabolites, as well as high secretion of growth hormone, catecholamines and cortisol (Kang et al., 2003). For optimal benefits specifically related to the lower exercise RPE, the type of exercise performed with higher intensity (or higher perceived exertion), could be performed earlier in the exercise session. This idea has already been presented, yet should be taken with caution (Kang et al., 2003).

In conclusion, the inverse sequence of bench-step aerobics and resistance exercise did not affect the BP responses neither during nor after exercise, but did affect $\mathrm{VO}_{2}, \mathrm{HR}$, body temperature, PSI and RPE responses. When starting with bench-step aerobics, there was a higher body temperature maintained during the subsequent resistance exercise, probably because of the vigorous intensity and the large amount of muscle mass involved. Accordingly, resistance exercise promoted lower $\mathrm{VO}_{2}$, a higher $\mathrm{HR}$ and physiologic strain index. In both cases, the exercise performed first was pointed out with a lower perceived exertion. Despite the different sequences, this exercise load combination promoted an acute post-exercise BP decrease, for at least one-hour in these normotensive participants.

\section{Acknowledgements}

This project was financed by national funds by the FCT - Fundação para a Ciência e Tecnologia, under the reference UID04045/2020.

\section{References}

Borg G. Borg'S RPE - Its Value for Sports Testing. New York: Movement Publications; 1985.

Borsheim E, Bahr R. Effect of exercise intensity, duration and mode on post-exercise oxygen consumption. Sports Med, 2003; 33(14): 1037-1060

Drummond J, Vehrs R, Schaalje B, Parcell C. Aerobic and resistance exercise sequence affects excess postexercise oxygen consumption. J Strength Cond Res, 2005; 19(2): 332-337

Figueroa A, Vicil F. Post-exercise aortic hemodynamic responses to low-intensity resistance exercise with 
and without vascular occlusion. Scand J Med Sci Sport, 2011; 21(3): 431-436

Forjaz L, Cardoso G, Rezk C, Santaella F, Tinucci T. Postexercise hypotension and hemodynamics: the role of exercise intensity. J Sport Med Phys Fitness, 2004; 44(1): 54-62

Forjaz L, Matsudaira Y, Rodrigues B, Nunes N, Negrao E. Post-exercise changes in blood pressure, heart rate and rate pressure product at different exercise intensities in normotensive humans. Braz J Med Biol Res, 1998; 31(10): 1247-1255

Garber E, Blissmer B, Deschenes R, Franklin A, Lamonte J, Lee M, Niemen D, Swain D. Quantity and Quality of Exercise for Developing and Maintaining Cardiorespiratory, Musculoskeletal, and Neuromotor Fitness in Apparently Healthy Adults: Guidance for Prescribing Exercise. Med Sci Sport Exer, 2011; 43(7): 1334-1359

Goto K, Higashiyama M, Ishii N, Takamatsu K. Prior Endurance Exercise Attenuates Growth Hormone Response to Subsequent Resistance Exercise. Med Sci Sport Exer, 2005; 37: S240-S240

Izquierdo M, Ibanez J, Hakkinen K, Kraemer J, Larrion L, Gorostiaga M. Once weekly combined resistance and cardiovascular training in healthy older men. Med Sci Sport Exer, 2004; 36(3): 435-443

Kang J, Rashti L, Tranchina P, Ratamess A, Faigenbaum D, Hoffman R. Effect of preceding resistance exercise on metabolism during subsequent aerobic session. Eur J Appl Physiol, 2009; 107(1): 43-50

Kang J, Schweitzer S, Hoffman R. Effect of order of exercise intensity upon cardiorespiratory, metabolic, and perceptual responses during exercise of mixed intensity. Eur J Appl Physiol, 2003; 90(5-6): 569-574

Keese F, Farinatti P, Pescatello L, Cunha A, Monteiro D. Aerobic exercise intensity influences hypotension following concurrent exercise sessions. Int J Sports Med, 2012; 33(2): 148-153

Keese F, Farinatti P, Pescatello L, Monteiro W. A comparison of the immediate effects of resistance, aerobic, and concurrent exercise on postexercise hypotension. J Strength Cond Res, 2011; 25(5): 1429-1436

Kraemer J, Fry A. Strength testing: development and evaluation methodology. In P. Maud \& C. Foster (Eds.), Physiological assessment of human fitness. Champaign: Human Kinetics, 115-138; 1995

Kraemer J, Keuning M, Ratamess A, Volek S, McCormick M, Bush A, Nindl C, Gordon E, Mazzetti A, Newton U, Gómez L, Wickham B, Rubin R, Hakkinen K. Resistance training combined with benchstep aerobics enhances women's health profile. Med Sci Sport Exer, 2001; 33(2): 259-269

Kraemer J, Patton F, Gordon E, Harman A, Deschenes R, Reynolds K, Newton U, Triplett T, Dziados E. Compatibility of High-Intensity Strength and Endurance Training on Hormonal and Skeletal-Muscle Adaptations. J Appl Physiol, 1995; 78(3): 976-989

Larose J, Sigal J, Khandwala F, Kenny P. Comparison of strenght development with resistance training and combined exercise in type 2 diabetes. Scand J Med Sci Sport, 2012; 22: e45-e54

Linsenbardt $\mathrm{T}$, Thomas R, Madsen W. Effect of breathing techniques on blood pressure response to resistance exercise. Brit J Sport Med, 1992; 26(2): 97-100

McArdle WD, Katch FI, Pechar GS, Jacobson L, Ruck S. Reliability and Interrelationships between Maximal Oxygen Intake, Physical Work Capacity and Step-Test Scores in College Women. Med Sci Sport Exer, 1972; 4(4): 182-186

MacDonald R. Potential causes, mechanisms, and implications of post exercise hypotension. J Hum Hypertens, 2002; 16(4): 225-236

MacDonald R, MacDougall D, Interisano A, Smith M, McCartney N, Moroz S, Younglai V, Tarnopolsky A. Hypotension following mild bouts of resistance exercise and submaximal dynamic exercise. Eur J Appl Physiol O, 1999; 79(2): 148-154

Moran DS, Shitzer A, Pandolf KB. A physiological strain index to evaluate heat stress. Am J Physiol Regul Integr Comp Physiol, 1998; 275: R129-34

Nelson G, Arnall A, Loy F, Silvester J, Conlee K. Consequences of Combining Strength and Endurance Training Regimens. Phys Ther, 1990; 70(5): 287-294

Netea T, Lenders M, Smits $\mathrm{P}$, Thien T. Both body and arm position significantly influence blood pressure measurement. J Hum Hypertens, 2003; 17(7): 459-462

Pescatello S, Franklin A, Fagard R, Farquhar B, Kelley A, Ray A. American College of Sports Medicine position stand. Exercise and hypertension. [Review]. Med Sci Sport Exer, 2004; 36(3): 533-553

Pescatello S, Guidry A, Blanchard E, Kerr A, Taylor L, Johnson N, Maresh M, Rodrigues N, Thompson D. Exercise intensity alters postexercise hypotension. J Hypertens, 2004; 22(10): 1881-1888

Pollock L, Gaesser A, Butcher D, Despres P, Dishman K, Franklin A, Garber E. The recommended quantity 
and quality of exercise for developing and maintaining cardiorespiratory and muscular fitness, and flexibility in healthy adults. Med Sci Sport Exer, 1998; 30(6): 975-991

Rezk C, Marrache C, Tinucci T, Mion D, Forjaz L. Post-resistance exercise hypotension, hemodynamics, and heart rate variability: influence of exercise intensity. Eur J Appl Physiol, 2006; 98(1): 105-112

Ruiz J, Simao R, Saccomani G, Casonatto J, Alexander L, Rhea M, Polito D. Isolated and combined effects of aerobic and strength exercise on post-exercise blood pressure and cardiac vagal reactivation in normotensive men. J Strength Cond Res, 2011; 25(3): 640-645

Schumann M, Yli-Peltola K, Abbiss R, Hakkinen K. Cardiorespiratory Adaptations during Concurrent Aerobic and Strength Training in Men and Women. Plos One, 2015; 10(9): e0139279

Smelker L, Foster C, Maher A, Martinez R., Porcari P. Effect of exercise intensity on postexercise hypotension. J Cardiopul Rehabil, 2004; 24(4): 269-273

\section{Corresponding author:}

\section{Catarina Abrantes}

Research Center in Sports Sciences, Health Sciences and Human Development, CIDESD, GERON Research Community, Portugal, Sport Sciences,

Exercise and Health Department, University of Trás-os-Montes and Alto Douro,

Portugal, www.utad.pt.

Address: Quinta de Prados, 5001-801 Vila Real, PORTUGAL

Phone number: +351934286001; Tel.: +351259350890

E-mail: abrantes@utad.pt 